\title{
Ecological diet and heart disease studies-a challenge for policy makers
}

\author{
W. Philip T James ${ }^{1}$
}

Received: 10 May 2018 / Accepted: 10 May 2018 / Published online: 18 June 2018

(c) Macmillan Publishers Limited, part of Springer Nature 2018

Kromhaut et al.'s interesting and careful reanalysis [1] of the groundbreaking Seven-Country Study [2] is important as it faces head on some of the criticisms of the original analysis amid a flurry of contemporary proposals that fat intakes are unimportant in promoting or causing coronary heart disease (CHD) [3] and that sugar has been neglected [4]. This arena has a long history of controversy and Ancel Keys, the principal instigator of these collaborative international studies, was himself notorious for his combative style. Indeed, I witnessed this myself when he furiously attacked me during an otherwise pleasurable dinner in Rome. He thought I had been proposing that high total fat induced CHD rather than helping to induce weight gain as I had actually set out [5].

Now, we have Kromhaut et al. [1] basing their new statistical analyses on far more detailed 1987-1988 chemical analyses of each centre's average intake of foods reconstructed at that time from the detailed records of the late 1950s and early 1960s intake of the middle-aged men in 13 of the 16 centres; in the remaining three centres food records were obtained about 10 years later. These new analyses, as well as a careful collation of foods to reflect Fidanza's original food grouping for representing the varied Mediterranean dietary patterns, have then been coupled with a detailed 50-year-long assessment of CHD mortality rates in the different centres. The dietary analyses in Wageningen in the Netherlands included new fibre analyses and also enzymatically analysed sugars, so this provides a far more detailed assessment of the dietary carbohydrate component than was usually made in the United States where total carbohydrates were estimated by the residual dry weight of foods once fat and crude protein

W. Philip T James

jeanhjames@aol.com

1 Nutrition, London School of Hygiene \& Tropical Medicine, Keppel Street, London WC1E 7HT, UK measurements had been made together with an allowance for the meal's ash content. If the fibre content was ever estimated in the United States, it was usually by Van Soest's method for measuring the insoluble crude fibre-lignin content used in cattle feeds. In addition, Kromhaut et al. now include detailed fatty acid analyses, including trans fat based on gas chromatographic and infra-red analyses.

The finding that the average population sucrose intake was positively associated with 50-year CHD mortality rates but naturally occurring sugars were not related is new. But the dilemma is that sucrose and saturated fat intakes across the 16 centres were also correlated albeit that the individual saturated fatty acids known to increase blood cholesterol levels had high correlations of $>0.8$ with CHD. Keys dismissed his own observed sugar effect in multivariate analyses, but Kromhaut et al. note that this is not appropriate when the two intakes are so well correlated. So now one wonders what Keys would have made of these new analyses? I guess he would have still emphasised the importance of saturated fats because he had already conducted a large number of metabolic studies showing that saturated fatty acids have individually differing capacities to increase total blood or cholesterol [6]. Keys had also already noted the importance of blood cholesterol levels in promoting atherosclerosis in animal studies [7], but at that stage, the animal experiments had not revealed the details of the induction of atherosclerosis and how hypertension and smoking increased the mucosal lesion but only if the background lipid induced by mucosal damage was underway. Later, these human dietary metabolic analyses together with later primate studies were corroborated by further rigorous analyses by Hegsted in Boston [8, 9]. The marked increases in LDL and total cholesterol contrast vividly with the difficulty to discern small increases in lipids when sugars are fed [10] as noted by Kromhaut et al. They also recognise that sugar promoting weight gain is important but in the Seven-Country Study, the Greek islanders were the heaviest on their relatively high olive-oil diet but were often shepherds undertaking extraordinarily prolonged daily 
climbing and walking activity, as witnessed by Anthony Kafatos when helping with the study as a young medical student (personal communication). These Greek islanders had nearly as low a CHD rate as the Japanese-perhaps a reflection of their exercise patterns despite their higher saturated fat intakes.

Keys clearly understood the importance of coupling results from cohort-based correlations to disease outcomes with a mechanistic understanding of the pathophysiological basis for the development of disease. His crude use of average cohort saturated fat intakes to CHD outcomes also stemmed from his detailed analyses of the fivefold variation between individuals in their blood cholesterol responses to the same saturated intake [11]. The repeatedly demonstrated individual metabolic responsiveness to a dietary component-whether fatty acids, minerals or macronutrients-is why cohort studies are such a poor means of establishing a causal relationship between diet and a disease outcome.

Unfortunately, this fundamental feature of individual dietary responsiveness and the importance of metabolic and mechanistic analyses is ignored in the current reliance by WHO and indeed most national authorities on using the GRADE system with usually a reliance on dietary cohort analyses for generating dietary policy [12]. This means that when cohort studies have at the most a twofold variation in individual intake, the individual variation in response often shows a nil or minimum effect and a positive result may be bedevilled by dietary or outcome measurement errors. The WHO approach in turn stemmed from the WCRF expert epidemiologically dominated group's reliance on cohort analyses of diet and cancer in developing their second diet and cancer report where it was recognised that there were no known readily measurable pathophysiologically important metabolic mediators of the carcinogenic process [13]. Yet, whenever possible, one needs both a good biomarker of intake and a real mechanistic understanding of dietary involvement in the disease process with some pathophysiologically important biomarkers such as blood lipid levels when considering the development of CHD. Kromhaut et al. clearly understand the limitations of these cohort analyses but their paper is a rigorous approach to the problem with excellent dietary analyses and meticulous long-term monitoring of CHD mortality rates.

\section{Compliance with ethical standards}

Conflict of interest The authors declare that they have no conflict of interest.

\section{References}

1. Kromhout D, Menotti A, Alberti-Fidanza A, Puddu PE, Hollman $\mathrm{P}$, Kafatos A, Tolonen H, Adachi H, Jacobs DR. Comparative ecologic relationships of saturated fat, sucrose, food groups, and a Mediterranean food pattern score to 50-year coronary heart disease mortality rates among 16 cohorts of the Seven Countries Study. Eur J Clin Nutr. 2018.

2. Keys A, Aravanis C, Blackburn H, Buzina R, Djordjevic BS, Dontas AS, et al. Seven Countries Study. A multivariate analysis of death and coronary heart disease. Cambridge, MA: Harvard University Press; 1980. p. 1-381.

3. Taubes G. Good calories, bad calories. Challenging the conventional wisdom on diet, weight control, and disease. New York: Alfred A. Knopf; 2008.

4. Lustig RH, Schmidt LA, Brindis CD. Public health: the toxic truth about sugar. Nature. 2012;482:27-9.

5. James WP, Trayhurn P. An integrated view of the metabolic and genetic basis for obesity. Lancet. 1976;2:770-3.

6. Keys A, Anderson JT, Grande F. Prediction of serum-cholesterol responses of man to changes in fats in the diet. Lancet. 1957;273:959-66.

7. Keys A. Human atherosclerosis and the diet. Circulation. 1952;5:115-8.

8. Hegsted DM, Ausman LM, Johnson JA, Dallal GE. Dietary fat and serum lipids: an evaluation of the experimental data. Am J Clin Nutr. 1993;57:875-83. Erratum in: Am J Clin Nutr. 1993;58:245

9. Nicolosi RJ, Stucchi AF, Kowala MC, Hennessy LK, Hegsted DM, Schaefer EJ. Effect of dietary fat saturation and cholesterol on LDL composition and metabolism. In vivo studies of receptor and nonreceptor-mediated catabolism of LDL in cebus monkeys. Arterioscler Thromb Vasc Biol. 1990;10:119-28.

10. Te Morenga LA, Howatson AJ, Jones RM, Mann J. Dietary sugars and cardiometabolic risk: systematic review and metaanalyses of randomized controlled trials of the effects on blood pressure and lipids. Am J Clin Nutr. 2014;100:65-79.

11. Jacobs DR Jr, Anderson JT, Hannan P, Keys A, Blackburn H. Variability in individual serum cholesterol response to change in diet. Arteriosclerosis. 1983;3:349-56.

12. Atkins D, Eccles M, Flottorp S, Guyatt GH, Henry D, Hill S, et al. 1 Systems for grading the quality of evidence and the strength of recommendations I: critical appraisal of existing approaches. The GRADE Working Group. BMC Health Serv Res. 2004;4:38.

13. World Cancer Research Fund, American Institute for Cancer Research. Food, nutrition, physical activity and the prevention of cancer: a global perspective. Washington, DC: American Institute for Cancer Research; 2007. 